УДК 373+612.776.1

\title{
ФИЗИЧЕСКАЯ РАБОТОСПОСОБНОСТЬ ПОДРОСТКОВ В ЗОНЕ БОЛЬШОЙ МОЩНОСТИ
}

\author{
Раевский Дмитрий Александрович \\ кандидат педагогических наук, доцент \\ Государственный университет управления \\ Зайцева Галина Алексеевна \\ кандидат педагогических наук, доцент \\ Национальный исследовательский \\ технологический университет "МИСиС" \\ Чернова Мария Борисовна \\ кандидат педагогических наук, доцент \\ ФГБНУ «Институт возрастной физиологии \\ Российской академии образования»
}

\begin{abstract}
Аннотация. Цель работы - выявить особенности физической работоспособности и двигательной подготовленности подростков, проявляемой в зоне большой мощности, с учетом стадий полового созревания.

Анализ результатов исследования показал, что школьники 13-15 лет, находящиеся на разных стадиях полового созревания, отличаются по уровню физической работоспособности, проявляемой в зоне большой мощности. Установлено, что с увеличением стадии полового созревания происходят волнообразные изменения рассматриваемых показателей физического состояния организма. В ряде случаев между подростками, находящимися на первой и пятой стадиях полового созревания, наблюдаются существенные различия.
\end{abstract}

Ключевые слова: зона большой мощности; работоспособность и двигательная подготовленность; половое созревание; смешанное аэробноанаэробное энергообеспечение. 


\title{
PHYSICAL WORKING CAPACITY ADOLESCENTS IN THE ZONE OF HIGH POWER
}

\author{
Raevsky Dmitry Alexandrovich \\ $\mathrm{PhD}$ (Cand. Ped. Sci.), associate professor, \\ State University of Management \\ Zaytseva Galina Alekseevna \\ $\mathrm{PhD}$ (Cand. Ped. Sci.), associate professor \\ National Research Technological University "MISiS" \\ Chernova Maria Borisovna \\ $\mathrm{PhD}$ (Cand. Ped. Sci.), Associate Professor \\ Institute of Developmental Physiology of the \\ Russian Academy of Education"
}

\begin{abstract}
The study aim is to identify the peculiarities of physical performance and motor fitness of adolescents manifested in high power zone at different stages of puberty.

The analysis of the study results showed that 13-15-year-old schoolchildren at different stages of puberty had different levels of physical performance manifested in high power zone. The progression of puberty was found to cause wave-like changes in the studied parameters of the body's physical state. In some cases, significant differences are observed between adolescents in the first and fifth stages of puberty.
\end{abstract}

Key words: zone of high power; working capacity and physical fitness; puberty; mixed aerobic-anaerobic energy supply.

Выявление возрастных и индивидуальных особенностей физической работоспособности человека на разных этапах развития является одной из актуальных задач возрастной физиологии мышечной деятельности и смежных с ней медико-биологических дисциплин. Особенно важны сведения о специфике изменений функциональных возможностей организма при выполнении физической работы различной относительной мощности в пубертатный период, в ходе которого существенно изменяются скорость и направленность процессов роста и развития, а количественные изменения чередуются с качественными преобразованиями в деятельности всех 


\section{МОДЕРНИЗАЦИЯ СОВРЕМЕННОГО ОБРАЗОВАНИЯ: АНАЛИЗ ОПЫТА И ТЕНДЕНЦИЙ}

физиологических систем организма и механизмов энергообеспечения мышечной деятельности $[14,11,5,12]$. По имеющимся данным функциональные возможности систем вегетативного обеспечения деятельности и нейро-эндокринной регуляции физиологических функций, мощность, емкость и эффективность аэробного и анаэробных механизмов мышечной энергетики у подростков по-разному изменяются в ходе полового созревания $[6,7,10,13,9]$.

В этой связи повышенный интерес представляет анализ динамики физической работоспособности, проявляемой в зоне большой мощности и характеризующейся смешанным аэробно-анаэробным энергообеспечением мышечной деятельности, по мере перехода от начальных к завершающим стадиям полового созревания (СПС).

Цель работы - выявить с учетом стадий полового созревания особенности физической работоспособности и двигательной подготовленности подростков, проявляемые в зоне большой мощности.

\section{Методика}

В исследовании участвовали практически здоровые подростки 13-15 лет $(\mathrm{n}=168)$. Определение стадий полового созревания (СПС) проводилось по методике Таннера, модифицированной Колесовым и Сельверовой [4]: I. препубертат; II стадия - этап активации гипофиза; III стадия - этап активации гонад; IV стадия - этап активного стероидогенеза; V стадия завершение пубертата.

Оценку величины физической работоспособности по тесту PWC170 и определение ватт-пульса (ВтП) проводили на основе использования одномоментной пробы в модификации Абросимовой Л.И. Для расчета PWC170 применялась динамическая физическая нагрузка, дозируемая с помощью велоэргометра. Работа выполнялась в течение 3-х минут, темп педалирования составлял 60 об/мин. Интенсивность нагрузки подбиралась таким образом, чтобы ЧСС во время её выполнения была не ниже 140 уд/мин. Вместо второй нагрузки использовались данные, полученные в состоянии спокойного бодрствования - ЧСС покоя и мощность работы, равная нулю.

Индивидуальный уровень максимального потребления кислорода (МПК) предсказывали посредством непрямого способа его определения [3]. В процессе тестирования испытуемый выполнял одну динамическую нагрузку циклического характера, в конце которой определялся пульс (высота 
ступеньки - 35 см, а темп восхождения - 30 циклов в минуту). МПК рассчитывали по формуле Добельна. При расчетах использовали поправочный коэффициент, учитывающий отрицательную механическую работу при спуске со ступеньки.

Показатель интенсивности накопления пульсового долга (ИНПД) использовался для оценки физиологической стоимости работы смешанной направленности. В ходе тестирования определялся пульсовой долг за 5 минут восстановления после нагрузки большой мощности. Полученная величина относилась к длительности удержания нагрузки.

На основе эргометрического подхода, базирующегося на анализе зависимости «мощность-время», рассчитывали показатель мощности нагрузки, максимальное время выполнения которой составляет 240 с (W240) [1].

Для оценки общей выносливости использовался тест «Бег 6 минут». Данный тест выполнялся на дорожке стадиона (на ней через каждые 20 метров наносилась разметка). В забеге принимало участие не более 3-5 подростков. Испытуемые мотивировались на преодоление как можно большей дистанции.

Статистический анализ данных проводили с использованием пакета прикладных статистических программ. В ходе исследования применялись параметрические критерии значимости оценок.

\section{Результаты исследования и их обсуждение}

Полученные результаты (рис.) указывают на выраженные различия в уровне работоспособности, проявляемой в зоне большой мощности, у подростков 13-15 лет с разными стадиями полового созревания (СПС).

На І СПС величина МПК составила в среднем 45,5 2,0 л/мин*кг,

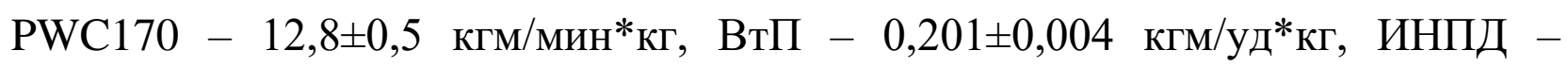
$0,39 \pm 0,08$ уд/c, W240 - 3,43 $\pm 0,08$ Вт/кг, бег 6 мин - 1246 \pm 16 м.

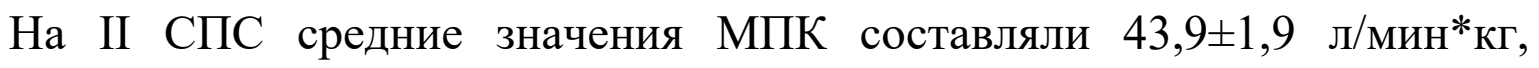

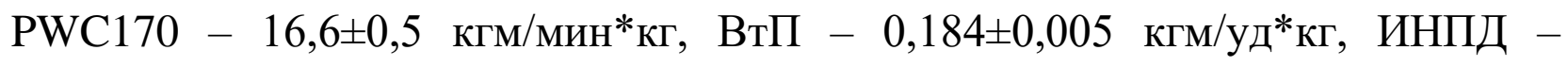

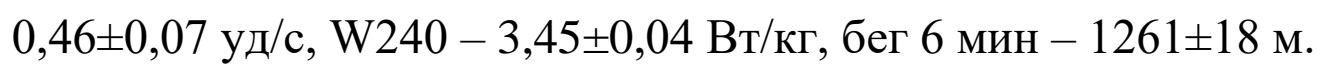

На III СПС средние значения МПК находились в границах 42,2 22,4

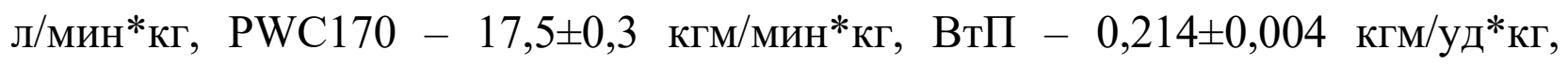

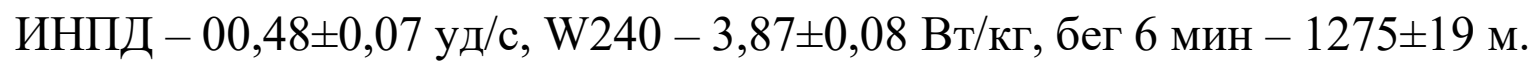




\section{МОДЕРНИЗАЦИЯ СОВРЕМЕННОГО ОБРАЗОВАНИЯ: АНАЛИЗ ОПЫТА И ТЕНДЕНЦИЙ}

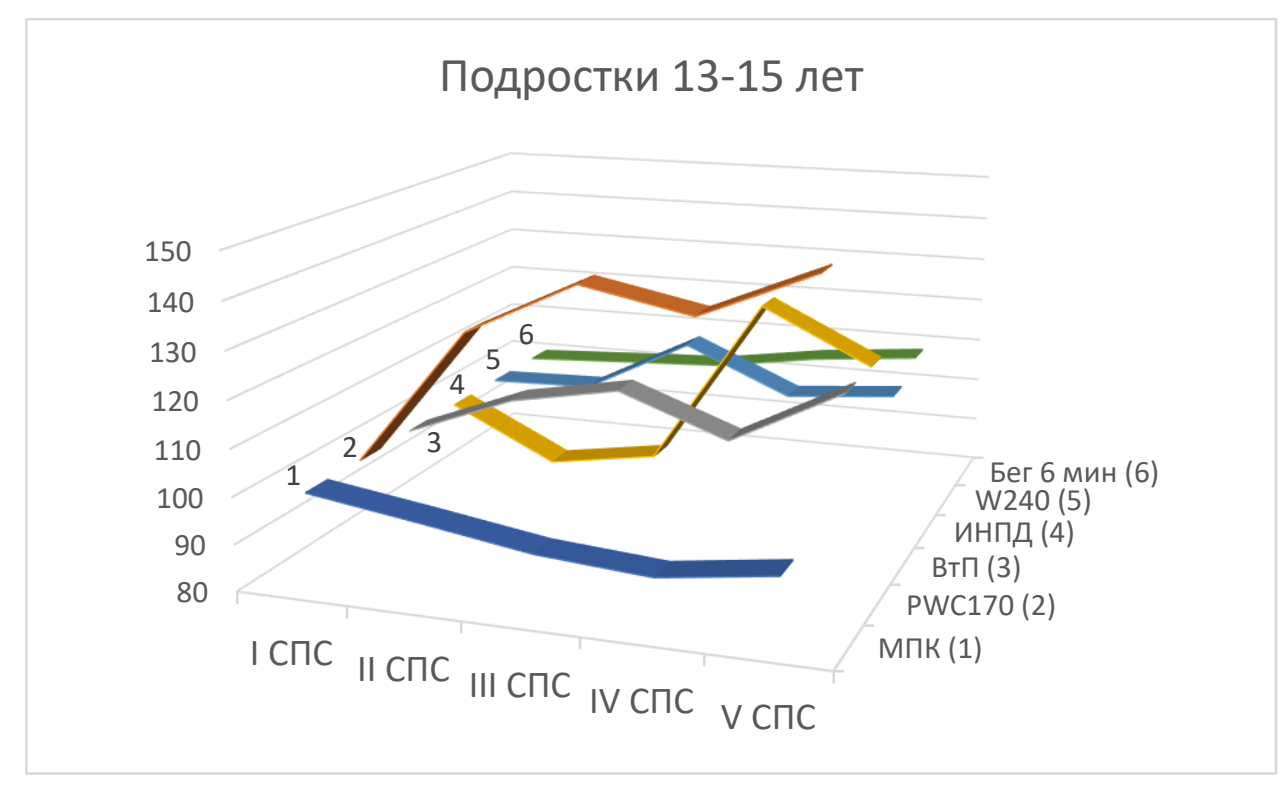

\section{Рис. 1. Динамика показателей работоспособности (в \%) в зоне большой мощности в зависимости от стадий полового созревания (СПС).}

Примечание. Величины показателей, полученные на І СПС, принималась за 100 \%, значения показателей на всех других СПС выражались в \% от I СПС.

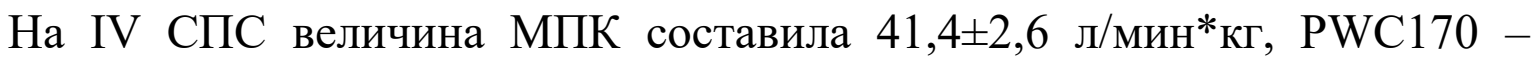

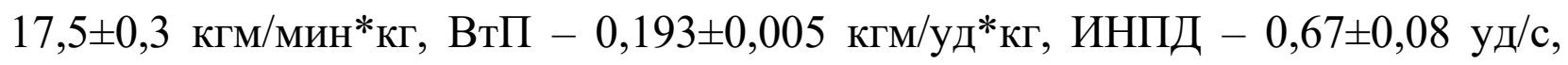
$\mathrm{W} 240-3,52 \pm 0,07 \mathrm{BT} / к г$, бег 6 мин $-1319 \pm 14$ м.

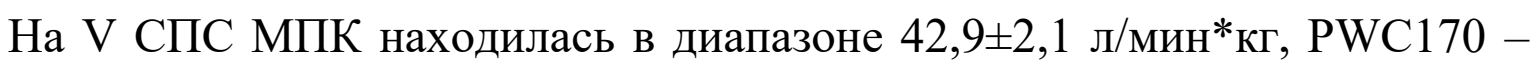

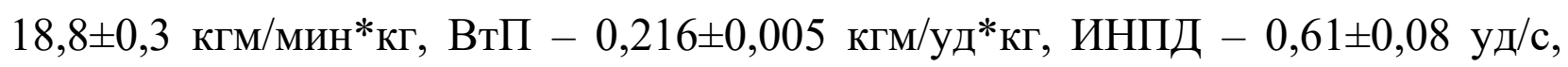

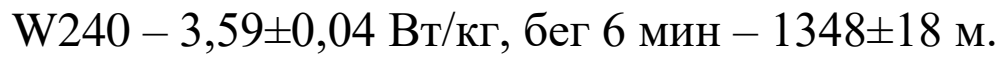

Анализ динамики работоспособности показал, что в зоне большой мощности по мере полового созревания наблюдаются волнообразные изменения рассматриваемых показателей (см. рис.), при этом между подростками с I и V СПС обнаружены статистически значимые ( $<0.05-0.001)$ в отношение средних величин $\mathrm{PWC}_{170}$, ватт-пульса и шестиминутного бега. По уровню МПК, ИНПД и $\mathrm{W} 240$ различия между $\mathrm{I}$ и $\mathrm{V}$ СПС были несущественными.

Зависимость интенсивности физической работы от её продолжительности в логарифмической шкале представляет собой ломаную линию, состоящую из четырех отрезков, соответствующих разным зонам относительной мощности [8]. Ведущие факторы энергообеспечения мышечной деятельности и механизмы регуляции физиологических функций, 


\section{МОДЕРНИЗАЦИЯ СОВРЕМЕННОГО ОБРАЗОВАНИЯ: АНАЛИЗ ОПЫТА И ТЕНДЕНЦИЙ}

определяющие физическую работоспособность в зоне большой мощности, существенно отличаются от зон максимальной, субмаксимальной и умеренной мощности [2]. Поэтому в настоящем исследовании отдельно проводился анализ динамики работоспособности в зоне большой мощности с учетом перехода от начальных к завершающим стадиям полового созревания. Выявлено, что с увеличением стадии полового созревания наблюдается существенный прирост функциональных возможностей, обеспечивающих повышение физической работоспособности подростков в зоне большой мощности. Можно полагать, что увеличение работоспособности в этой зоне относительной мощности происходит по мере полового созревания преимущественно за счет нарастания относительного вклада анаэробных механизмов энергетического обеспечения мышечной деятельности и уменьшения доли аэробного источника. Полученные результаты хорошо согласуется с данными других исследований, показавших, что в отличие от аэробных способностей, дефинитивный уровень параметров анаэробного алактатного и анаэробного гликолитического энергообеспечения мышечной деятельности формируется к окончанию периода полового созревания $[20,13,9,12]$.

\section{Заключение}

Анализ полученных результатов показал, что школьники 13-15 лет, находящиеся на разных стадиях полового созревания, отличаются по уровню физической работоспособности, проявляемой в зоне большой мощности. Установлено, что по мере перехода от первой к пятой стадии полового созревания происходят волнообразные изменения рассматриваемых показателей физического состояния организма. В ряде случаев между подростками, находящимися на первой и пятой стадиях полового созревания, наблюдаются существенные различия.

Полученные результаты дают основание считать, что подростки, различающиеся по стадиям полового созревания, характеризуются спецификой физической работоспособности и двигательной подготовленности в зоне большой мощности. Выявленную специфику необходимо учитывать при разработке программ физического воспитания школьников подросткового возраста, а также при отборе средств, методов и технологий улучшения физического состояния и укрепления здоровья учащихся основной школы. 


\section{Примечание}

Работа поддержана РФФИ (грант № 20-013-00111a).

\section{Список литературы}

1. Баранцев, С.А. Формирование кинематической структуры ациклических локомоций и биоэнергетики мышечной системы мальчиков школьного возраста / С.А. Баранцев, В.В. Зайцева, Д.М. Пискова // Новые исследования. - 2009. - №3(20). - С. 62-72.

2. Волков, Н.И. Биоэнергетика спорта: Монография Н.И. Волков, В.И. Олейников. - М.: Советский спорт, 2011. - 160 с.

3. Карпман, В.Л. Тестирование в спортивной медицине/ В.Л. Карпман, 3.Б. Белоцерковский, И.А. Гудков. - М.: Физкультура и спорт, 1988. - 208 с.

4. Колесов, Д.В. Физиолого-педагогические аспекты полового созревания /Д.В. Колесов, Н.Б. Сельверова. - М.: Педагогика. 1978. - 224 с.

5. Криволапчук, И.А. Особенности факторной структуры физической работоспособности мальчиков и девочек 9-10 лет / И.А. Криволапчук, В.В. Мышьяков // Гигиена и санитария, 2017. - № 8. - С. 759-765.

6. Криволапчук, И.А. Энергообеспечение мышечной деятельности у мальчиков 13-14 лет в зависимости от темпов полового созревания/ И.А. Криволапчук // Физиология человека. - 2011.- Т.37, №1. - С. 85-96.

7. Тамбовцева, Р.В. Ферментативные преобразования мышечной ткани в постнатальном онтогенезе / Р.В. Тамбовцева // Международный журнал экспериментального образования. - 2016. № 12. - С. 124-127.

8. Фарфель, В.С. Управление движениями в спорте /В.С. Фарфель. - М.: Физкультура и спорт. 1975. - 208 с.

9. Almeida-Neto, P.F. Can the Neuromuscular Performance of Young Athletes Be Influenced by Hormone Levels and Different Stages of Puberty? / P.F. AlmeidaNeto, D.G. de Matos, V.C.M. Pinto, P.M.S. Dantas, T.M. Cesário, L.F. da Silva, A. Bulhões-Correia, F.J. Aidar, B.G.A.T. Cabral // Int J Environ Res Public Health. 2020. Vol. 17(16). - P. 5637.

10. Armstrong, N. Clarity and Confusion in the Development of Youth Aerobic Fitness / N.Armstrong, J.Welsman // Front Physiol. - 2019. Vol. 30;10. - P. 979.

11. Armstrong, N. Top 10 Research Questions Related to Youth Aerobic Fitness /N. Armstrong // Res Q Exerc Sport. 2017. vol. 88(2), pp. 130-148. 
12. Batista M.B. Independent and Combined Effects of Weight Status and Maturation on Aerobic Fitness in Adolescent School-Aged Males / M.B. Batista, J. Valente-Dos-Santos, J.P. Duarte, P. Sousa-E-Silva, M.J. Coelho-E-Silva, A.O. Werneck, D. Ohara, E.S. Cyrino, E.R.V. Ronque // J Strength Cond Res. - 2020. Vol. 34(9). - P. 2663-2671.

13. Beyer, K.S. Effect of somatic maturity on the aerobic and anaerobic adaptations to sprint interval training/ K.S. Beyer, J.R. Stout, M.J. Redd, K.M. Baker, D.D. Church, H.C. Bergstrom, J.R. Hoffman, D.H. Fukuda // Physiol Rep. - 2020. Vol. 8(9): e14426. doi: 10.14814/phy2.14426

14. Malina, R.M. Top 10 research questions related to growth and maturation of relevance to physical activity, performance, and fitness/ R.M. Malina // Res Q Exerc Sport. - 2014. Vol. 85(2). - P. 157-173.

(С) Д.А. Раевский, Г.А. Зайцева, М.Б. Чернова, 2021 